\title{
Role of Complementary and Alternative Medicine in Otolaryngologic Perioperative Care
}

\author{
Aron Kallush, BA, Charles A. Riley, MD, Ashutosh Kacker, MBBS, MD \\ Department of Otolaryngology, Weill Cornell Medical College, New York, NY
}

\begin{abstract}
Background: During the perioperative period for otolaryngologic surgical cases, complications and delays can occur as the result of anxiety, pain, nausea, and vomiting. Conventional methods used to treat these symptoms include medications that can be expensive and invasive or that can cause adverse effects. Because of the concerns about opioid use in the United States, providers might want to consider using complementary and alternative medicine (CAM) as adjunctive or primary treatment plans.
\end{abstract}

Methods: To assess the current knowledge about the clinical effectiveness of CAM for patients undergoing otolaryngologic procedures, we searched the literature using MEDLINE, PubMed, and Google Scholar. We excluded studies published prior to 1990 and articles about surgeries that were unrelated to otolaryngology.

Results: An analysis of the selected studies revealed that CAM therapies-acupuncture, aromatherapy, hypnosis, and music therapy-have been shown to be effective at reducing preoperative anxiety, postoperative pain, and postoperative nausea and vomiting. No adverse side effects were associated with CAM use in these studies.

Conclusion: The use of CAM in patients undergoing otolaryngologic surgeries may relieve common perioperative symptoms. While further study is warranted, otolaryngology providers might consider implementing CAM with patients electing surgery.

Keywords: Complementary and alternative medicine, literature review, otolaryngology, perioperative care

Address correspondence to Ashutosh Kacker, MBBS, MD, Department of Otolaryngology, Weill Cornell Medical College, 1305 York Avenue, 5th Floor, New York, NY 10021. Tel: (917) 573-1092. Email: ask9001@med.cornell.edu

\section{INTRODUCTION}

Perioperative care has improved since the late 1990s because of the multimodal approach to postoperative recovery. ${ }^{1}$ Because of the effectiveness of complementary and alternative medicine (CAM) in relieving various symptoms with minimal side effects, its use in modern surgical medicine is on the rise. ${ }^{2}$ An article published in 2010 reported that approximately $40 \%$ of adults in the United States use at least one form of CAM. ${ }^{3}$ However, because of insufficient data demonstrating the efficacy of CAM, some providers remain skeptical about using CAM during the perioperative period. Still, numerous studies have demonstrated that CAM may enhance perioperative patient care. ${ }^{4-6}$ Studies in the obstetrics ${ }^{7}$ and general surgery ${ }^{8}$ literature have suggested that implementing various CAM methods during the perioperative period may improve outcomes, decrease patient anxiety, reduce postoperative nausea and vomiting (PONV), and result in overall higher patient satisfaction. ${ }^{9}$

In the practice of otolaryngology, perioperative care is critical. Patients commonly experience pain, nausea, vomiting, and stress, and these symptoms can delay healing. ${ }^{10-12}$ Traditional treatments for these symptoms include analgesics and antiemetics that can be expensive and invasive or that can cause undesired side effects. ${ }^{13}$ Furthermore, given the concerns about pain medication addiction in the United States, alternative means to treat perioperative pain may have an important role in the future to limit the use of narcotic medications.

This review explores the effects of acupuncture, aromatherapy, hypnosis, and music therapy in improving subjective surgical experiences and perioperative outcomes.

\section{METHODS}

In January-February 2018, we searched the literature pertaining to CAM utilization in the perioperative period for patients undergoing otolaryngologic surgeries. Using MEDLINE, PubMed, and Google Scholar, we searched the following words and terms: otolaryngology, perioperative care, acupuncture, complementary medicine, postoperative tonsillectomy pain, postoperative management following otolaryngologic surgery, aromatherapy for management of preoperative stress and anxiety, and alternative forms of care for PONV following otolaryngologic surgeries. We excluded articles about surgeries that were unrelated to otolaryngology. We also excluded studies published prior to 1990 to limit the review to the contemporary literature. 


\section{RESULTS}

\section{Acupuncture}

Acupuncture originated in China approximately 2,500 years ago. ${ }^{14}$ The premise of the technique is that energy known as qi flows through the body via pathways known as meridians and that stimulation of acupuncture points throughout the body corrects energy imbalances and restores health. ${ }^{14}$ Thin, metallic needles, employed manually or by electrical stimulation, are used to puncture the skin at these acupuncture points. ${ }^{14}$ Although acupuncture is considered a safe procedure, adverse side effects can occur, including hemorrhage, hematoma, dizziness, nausea, syncope, and infection. ${ }^{15,16}$

In a 2016 study, Shin et al evaluated the antiemetic effects of acupuncture in pediatric patients who had undergone tonsillectomies. ${ }^{17}$ Their metaanalysis of 8 articles revealed that the incidence of PONV was significantly lower in the patients who received acupuncture treatment compared to the control group who received traditional antiemetic medications. The researchers concluded that administering acupuncture at pericardium 6 (PC6), located 3 fingerbreadths below the wrist on the inner forearm, is safe and effective at reducing PONV in pediatric patients after tonsillectomies. Similarly, Moeen compared the antiemetic effects of acupuncture at PC6 and CV13 (located 1 thumb breadth above the midpoint between the umbilicus and the xiphisternum) to dexamethasone in pediatric patients after tonsillectomy. ${ }^{18} \mathrm{~A}$ total of 120 children, $2-8$ years old, were enrolled in the randomized, double-blind study. At the start of anesthesia, the control group received intravenous (IV) dexamethasone and sham acupuncture, while the experimental group received acupuncture and IV saline. After assessing the incidence of vomiting in both groups, researchers concluded that acupuncture at PC6 and CV13 provided similar antiemetic effects as dexamethasone.

In another study, Ochi compared the effectiveness of acupuncture to codeine for posttonsillectomy pain in children in a retrospective review. ${ }^{19}$ Typically, throat pain after a traditional tonsillectomy can last 10-14 days. In total, 56 patients were included in the study, with 31 patients electing acupuncture treatment for pain relief. The average pain score on the visual analog scale (scored 0 to 10 with 0 representing no pain and 10 representing the worst pain imaginable) reported by patients prior to receiving acupuncture was 5.52. This score fell to a mean of 1.92 after the acupuncture treatment. Additionally, the mean duration of perceived pain relief from the intervention was 61.24 hours with no reported side effects. These results suggest that acupuncture intervention after pediatric tonsillectomies can be a safe and effective form of pain relief, while also minimizing the likelihood of adverse side effects.

Tsao et al and Gilbey et al also studied the effect of acupuncture on tonsillectomy pain in pediatric patients. ${ }^{13,20}$ The conclusions of both studies were that acupuncture administration is safe and effective at relieving postoperative tonsillectomy pain in pediatric patients, may cause an earlier return to a regular diet postoperatively, and is well accepted by children and their parents.

Acupuncture has also been shown to be effective in adult tonsillectomies. Cho et al conducted a metaanalysis examining studies that compared groups of patients who had re- ceived perioperative acupuncture to a control group who received either sham acupuncture or a traditional analgesic. ${ }^{21}$ The studies specifically measured postoperative pain intensity, analgesic consumption, or PONV, all of which were significantly lower in the acupuncture group than the control group. No major adverse effects were reported in the experimental group.

Acupuncture has demonstrated promising results after neck surgeries. Pfister et al performed a prospective, randomized, controlled trial to assess whether acupuncture can reduce pain and dysfunction in patients with cancer and a history of neck dissection surgery. ${ }^{22}$ The researchers also examined if acupuncture was an effective treatment strategy for relieving xerostomia, a common side effect after radiation. All 58 patients enrolled in the study from 2004-2007 had undergone neck dissection surgery and radiation and complained of neck or shoulder pain caused by their procedure. Patients who had received acupuncture within 6 weeks were excluded. The experimental group received acupuncture treatments once per week for 4 weeks, while the control group continued their usual care. Pain, function, and activities of daily living were assessed via the Constant-Murley scale, and xerostomia was also assessed. Patients who received the 4-week acupuncture intervention had significantly more improved ConstantMurley scores and a significantly greater improvement in xerostomia than the control group. Deganello et al compared the effect of acupuncture to traditional physical therapy for treating chronic neck pain after neck dissection. ${ }^{23}$ After completion of 5 weekly acupuncture sessions, the ConstantMurley scores improved significantly more in the patients who received acupuncture compared to the patients who received physical therapy.

Grech et al conducted a prospective double-blind study on 20 patients undergoing thyroid and parathyroid surgeries. $^{24}$ The experimental group received low-frequency electroacupuncture for 30 minutes during the maintenance phase of general anesthesia. Results revealed that the electroacupuncture group required $60 \%$ less analgesics in the postanesthesia care unit than the control group. In addition, the electroacupuncture group had significantly lower postoperative stress and hyperglycemia than the control group. Given that postoperative hyperglycemia is an insulinresistant process that may worsen inflammation and delay wound healing, this finding provides further weight to the perioperative value of acupuncture.

Sahmeddini et al compared the administration of electroacupuncture at specific points to sham acupuncture for complementary pain alleviation in patients who had undergone septoplasty. ${ }^{25}$ Researchers randomized 90 patients into an experimental electroacupuncture group or a control group that received IV meperidine and assessed the average time for the first analgesic request, as well as pain intensity on a $100-\mathrm{mm}$ visual analog scale. Postoperative pain intensity and respiratory depression were similar in both groups. However, the incidence of PONV was significantly lower in the acupuncture group than in the control group. Additionally, no adverse side effects were seen in the patients who received the acupuncture intervention.

Tong et al examined the effect of acupuncture treatment in conjunction with anesthesia in patients undergoing functional 
endoscopic sinus surgery (FESS) ${ }^{26}$ Ninety patients undergoing FESS were divided into 3 groups. Group A was given routine local anesthesia. Group $B$ received routine local anesthesia, as well as electroacupuncture for 30 minutes prior to administration of local anesthesia. Group $\mathrm{C}$ received a reduction in the local anesthesia after electroacupuncture intervention for 30 minutes. Groups $B$ and $C$ both received the acupuncture intervention at Yintang (EX-HN 3), the spot in the center of the top of the nose between both eyes, and Yingxiang (LI 20), the 2 spots at the bottom of the nose beside each nostril. After assessing for narcotic dosage, modified fingers pain scores, and postoperative satisfaction scores in the 3 groups, results demonstrated that the operative dosage of routine anesthesia was significantly different in the 3 groups. Group A required the highest dosage, while group $C$ required the lowest dosage. Moreover, the fingers pain scores in group $B$ and $C$ were lower than that of group $A$, and the postoperative satisfaction scores in group $B$ and $C$ were both higher than that of group $\mathrm{A}$. The researchers upheld the hypothesis that acupuncture may be effective at reducing pain, decreasing the required anesthesia dosage, and increasing patient satisfaction after FESS.

Table 1 summarizes these studies. All display the effectiveness of acupuncture at relieving a myriad of symptoms associated with a variety of otolaryngologic surgeries. A common feature of all of these studies is the lack of side effects. This result on its own should be deemed medically significant.

\section{Aromatherapy}

Aromatherapy is a holistic healing technique that is purported to unify psychological and physiologic processes to enhance the innate healing process. ${ }^{18,27}$ Essential oils extracted from aromatic plants can be administered topically, with massage, or by inhalation. ${ }^{27}$ Although the mechanism by which aromatherapy works is uncertain, experts believe that after the smell receptors in the nose relay messages to the limbic system in the brain, the essential oils act as anxiolytics and allow the patient to feel calm and relaxed. ${ }^{27-30}$

In a randomized, controlled trial, Soltani et al tested the effectiveness of aromatherapy with lavender essential oil on posttonsillectomy pain in pediatric patients. ${ }^{31}$ Forty-eight pediatric patients 6-12 years old were randomly assigned to 2 groups. After undergoing tonsillectomy, patients in both groups received $10-15 \mathrm{mg} / \mathrm{kg}$ of acetaminophen every 6 hours to relieve pain. Patients in the experimental group also inhaled lavender essential oil, while patients in the control group did not. Researchers recorded the frequencies of daily use of acetaminophen, nocturnal awakening because of pain, and pain intensity for 3 days after surgery. The study demonstrated that patients who were exposed to the lavender oil aromatherapy treatment had significant reductions in their daily need for acetaminophen in all 3 postoperative days. Although pain intensity and frequency of nocturnal awakening from pain did not differ between the 2 groups, researchers concluded that aromatherapy treatment with lavender essential oil decreased the amount of pain medication required for pediatric patients to treat posttonsillectomy pain.

Wotman et al conducted a prospective, controlled pilot study examining the effect of inhalation lavender aromatherapy on preoperative anxiety. ${ }^{32} \mathrm{~A}$ total of 100 patients admit- ted for ambulatory otolaryngologic surgery from January to August 2015 were included in the study. The experimental group received the aromatherapy treatment in addition to standard nursing care in the preoperative waiting area, while the control group received standard nursing care only. Both groups reported their level of anxiety using a visual analog scale prior to and after surgery. The researchers reported that the mean reduction in anxiety was statistically greater in the experimental group than the control group.

\section{Hypnosis}

Hypnosis is thought to cause changes in sensations, perceptions, thoughts, or behavior. ${ }^{33}$ When hypnosis is used as part of patient care, the hypnotist may induce the patient into a highly suggestible state, allowing the patient to more easily succumb to the suggestions of his or her medical providers. ${ }^{33,34}$ Although the way in which hypnosis works is not clear, a commonly accepted theory posits that during hypnosis, the hypnotist can work directly with the subject's subconscious. $^{35}$ Despite different ideas about how hypnosis works, studies have demonstrated its effectiveness during perioperative care.

In a comprehensive methodological review, Accardi and Milling examined the effectiveness of hypnosis for reducing pain after surgery in children and adolescents. ${ }^{36}$ Patients $\leq 19$ years underwent a variety of surgical operations, including tonsillectomies and adenoidectomies. Exposure to hypnosis, self-hypnosis, or hypnotic-like imagery was compared to distraction, attention control, play therapy, standard medical care, cognitive behavioral therapy, or no treatment at all. Results indicated that standard hypnosis did not significantly reduce pain more than play therapy or standard medical care. However, hypnotic-like imagery was associated with reduced postoperative pain and a shorter hospital stay. Additionally, in patients who received hypnosis as an adjunct with local anesthesia, pain levels were significantly reduced compared to patients who received local anesthetia alone or local anesthetia with attention control. The investigators concluded that different hypnotic techniques could be effective at relieving pain and discomfort in children after surgical operations.

Rapkin et al examined the effect of imagery-hypnosis on patients recovering from head and neck cancer surgery. ${ }^{37}$ Fifteen patients received preoperative hypnosis, and 21 patients received standard care with no hypnosis. Postoperative hospitalizations were significantly shorter for patients who had received the preoperative imagery-hypnosis compared to patients who did not receive the preoperative hypnosis treatment. Additionally, the study results showed that hypnotic imagery might be prophylactic, as investigators found a negative correlation between hypnosis and surgical complications.

\section{Music Therapy}

The use of music as a healing tool dates back thousands of years. ${ }^{38}$ The method relies on the relaxing properties of music to help repair, maintain, and improve the physiology and psychology of the individual's mind. Conrad et al conducted a randomized study to identify the mechanisms of music-induced relaxation and found that a musical intervention caused an increase in the concentration of plasma growth hormone and a decrease in interleukin- 6 and 
Table 1. Summary of Selected Studies Examining the Effects of Acupuncture in Association With Otolaryngologic Surgery

\begin{tabular}{|c|c|c|c|c|c|}
\hline Study & Study Design & $\begin{array}{l}\text { Number } \\
\text { of Patients }\end{array}$ & Surgery Type & Outcomes & Findings \\
\hline $\begin{array}{l}\text { Pfister } \\
\quad \text { et al, } 2010^{22}\end{array}$ & $\begin{array}{c}\text { Randomized, } \\
\text { controlled }\end{array}$ & 58 & $\begin{array}{l}\text { Neck } \\
\text { dissection }\end{array}$ & $\begin{array}{l}\text { Postoperative pain } \\
\text { and dysfunction }\end{array}$ & $\begin{array}{l}\text { Reduction in postoperative pain } \\
\text { and dysfunction compared to } \\
\text { usual care }(P=0.008)\end{array}$ \\
\hline $\begin{array}{l}\text { Sahmeddini } \\
\text { et al, } \\
2010^{25}\end{array}$ & $\begin{array}{c}\text { Randomized, } \\
\text { controlled }\end{array}$ & 90 & $\begin{array}{l}\text { Nasal } \\
\text { septoplasty }\end{array}$ & Postoperative pain & $\begin{array}{l}\text { Similar analgesic effect as } \\
\text { meperidine }(P>0.05) \text { and } \\
\text { reduction in PONV }(P<0.05)\end{array}$ \\
\hline $\begin{array}{l}\text { Tong et al, } \\
2012^{26}\end{array}$ & $\begin{array}{c}\text { Randomized, } \\
\text { controlled }\end{array}$ & 90 & $\begin{array}{l}\text { Functional } \\
\text { endoscopic } \\
\text { sinus surgery }\end{array}$ & Analgesic effect & $\begin{array}{l}\text { Reduction of postoperative } \\
\text { pain }(P<0.01) \text {, decreased } \\
\text { dosage of local anesthetic } \\
(P<0.01) \text {, increased patient } \\
\text { satisfaction scores }(P<0.01) \\
\text { compared to anesthesia } \\
\text { alone }\end{array}$ \\
\hline Ochi, $2013^{19}$ & $\begin{array}{l}\text { Retrospective } \\
\text { review }\end{array}$ & 56 & Tonsillectomy & Postoperative pain & $\begin{array}{l}\text { Reduction in postoperative pain } \\
(P<0.01) \text { compared to } \\
\text { codeine }\end{array}$ \\
\hline $\begin{array}{l}\text { Tsao et al, } \\
2015^{13}\end{array}$ & $\begin{array}{l}\text { Randomized, } \\
\text { controlled, } \\
\text { double-blind }\end{array}$ & 59 & Tonsillectomy & Postoperative pain & $\begin{array}{l}\text { Reduction in postoperative pain } \\
\text { compared to sham } \\
\text { acupuncture }(P=0.0065)\end{array}$ \\
\hline $\begin{array}{l}\text { Gilbey et al, } \\
2015^{20}\end{array}$ & $\begin{array}{l}\text { Randomized, } \\
\text { controlled, } \\
\text { single-blind }\end{array}$ & 60 & Tonsillectomy & $\begin{array}{l}\text { Pain and unwanted } \\
\text { side effects }\end{array}$ & $\begin{array}{l}\text { Reduction in pain with no } \\
\text { unwanted side effects } \\
(P \leq 0.01) \text { compared to } \\
\text { conventional postoperative } \\
\text { analgesic treatment alone }\end{array}$ \\
\hline $\begin{array}{l}\text { Shin et al, } \\
\quad 2016^{17}\end{array}$ & $\begin{array}{l}\text { Metaanalysis/ } \\
\text { systematic } \\
\text { review }\end{array}$ & 800 & Tonsillectomy & PONV & $\begin{array}{l}\text { Reduction in PONV }(P<0.05) \\
\text { and lower risk-ratio } \\
\text { compared to conventional } \\
\text { drug therapy }\end{array}$ \\
\hline $\begin{array}{l}\text { Moeen, } \\
2016^{18}\end{array}$ & $\begin{array}{l}\text { Prospective } \\
\text { double-blind }\end{array}$ & 120 & Tonsillectomy & Postoperative vomiting & $\begin{array}{l}\text { Similar antiemetic effects as } \\
\text { dexamethasone }(P=0.426)\end{array}$ \\
\hline $\begin{array}{l}\text { Cho et al, } \\
2016^{21}\end{array}$ & $\begin{array}{l}\text { Metaanalysis/ } \\
\text { systematic } \\
\text { review }\end{array}$ & 1,025 & Tonsillectomy & $\begin{array}{l}\text { PONV and postoperative } \\
\text { pain }\end{array}$ & $\begin{array}{l}\text { Reduction in PONV compared } \\
\text { to conventional analgesic } \\
\text { alone }\end{array}$ \\
\hline $\begin{array}{l}\text { Deganello } \\
\quad \text { et al, } 2016^{23}\end{array}$ & Pilot & 48 & Neck dissection & $\begin{array}{l}\text { Postoperative pain } \\
\text { and dysfunction }\end{array}$ & $\begin{array}{l}\text { Reduction in chronic pain and } \\
\text { dysfunction after neck } \\
\text { dissection }(P<0.01) \\
\text { compared to physical } \\
\text { therapy }\end{array}$ \\
\hline $\begin{array}{l}\text { Grech et al, } \\
2016^{24}\end{array}$ & $\begin{array}{l}\text { Prospective, } \\
\text { double-blind } \\
\text { pilot }\end{array}$ & 20 & $\begin{array}{l}\text { Thyroid and } \\
\text { parathyroid } \\
\text { surgery }\end{array}$ & $\begin{array}{l}\text { Analgesic use, pain, } \\
\text { physiologic stress, } \\
\text { immune cytokine } \\
\text { response }\end{array}$ & $\begin{array}{l}\text { Reduction in analgesic use, } \\
\text { glycemic levels }(P<0.005), \\
\text { and postoperative stress } \\
\text { compared to general } \\
\text { anesthesia alone }\end{array}$ \\
\hline
\end{tabular}

PONV, postoperative nausea and vomiting.

epinephrine. ${ }^{39}$ This reduction in stress hormones resulted in lower blood pressure and heart rate in patients who received the music therapy.

Tse et al tested the effectiveness of music therapy on postoperative pain management following nasal surgery. ${ }^{40}$ Fifty-seven patients aged 15-69 years were randomly assigned to an experimental group or a control group. Music was recurrently played to participants in the experimental group during the first 24 hours postoperatively. Intensity of pain was measured using the pain verbal rating scale. Patients in the experimental group had significant decreases in pain intensity over time compared to the patients in the control group. Additionally, the data indicated that patients exposed to the music therapy had a lower systolic blood pressure and heart rate and required fewer pain medications than patients in the control group. Table 2 summarizes 
Table 2. Summary of Selected Studies Examining the Effects of Hypnosis, Aromatherapy, and Music Therapy in Association With Otolaryngologic Surgery

\begin{tabular}{|c|c|c|c|c|c|c|}
\hline Study & Study Design & $\begin{array}{c}\text { Number } \\
\text { of Patients }\end{array}$ & $\begin{array}{l}\text { Treatment } \\
\text { Modality }\end{array}$ & Surgery Type & Outcomes & Findings \\
\hline $\begin{array}{l}\text { Rapkin } \\
\quad \text { et al, } 1991^{37}\end{array}$ & $\begin{array}{l}\text { Voluntary, } \\
\text { exploratory }\end{array}$ & 36 & Hypnosis & $\begin{array}{l}\text { Head and neck } \\
\text { cancer surgery }\end{array}$ & $\begin{array}{c}\text { Hypnosis } \\
\text { effect }\end{array}$ & $\begin{array}{l}\text { Negative correlations between } \\
\text { hypnosis and surgical } \\
\text { complications and blood loss }\end{array}$ \\
\hline $\begin{array}{l}\text { Accardi and } \\
\text { Milling, } \\
2009^{36}\end{array}$ & $\begin{array}{l}\text { Comprehensive } \\
\text { methodological } \\
\text { review }\end{array}$ & 528 & Hypnosis & $\begin{array}{l}\text { Tonsillectomy/ } \\
\text { adenoidectomy }\end{array}$ & $\begin{array}{l}\text { Postoperative } \\
\text { pain }\end{array}$ & $\begin{array}{l}\text { Reduction in postoperative pain } \\
\text { compared to patients who } \\
\text { did not undergo hypnosis }\end{array}$ \\
\hline $\begin{array}{l}\text { Soltani et al, } \\
2013^{31}\end{array}$ & $\begin{array}{c}\text { Randomized, } \\
\text { controlled }\end{array}$ & 48 & Aromatherapy & Tonsillectomy & $\begin{array}{l}\text { Postoperative } \\
\text { pain }\end{array}$ & $\begin{array}{l}\text { Reduction in required } \\
\text { analgesics after surgery } \\
\text { compared to the no- } \\
\text { aromatherapy group }\end{array}$ \\
\hline $\begin{array}{l}\text { Wotman } \\
\text { et al, } 2017^{32}\end{array}$ & $\begin{array}{l}\text { Prospective, } \\
\text { controlled pilot }\end{array}$ & 100 & Aromatherapy & $\begin{array}{l}\text { Tonsillectomy, } \\
\text { septoplasty, } \\
\text { functional } \\
\text { endoscopic } \\
\text { sinus surgery }\end{array}$ & $\begin{array}{l}\text { Preoperative } \\
\text { anxiety }\end{array}$ & $\begin{array}{l}\text { Reduction in preoperative } \\
\text { anxiety }(P<0.001) \text { compared } \\
\text { to the no-aromatherapy } \\
\text { group }\end{array}$ \\
\hline $\begin{array}{l}\text { Tse et al, } \\
2005^{40}\end{array}$ & $\begin{array}{c}\text { Randomized, } \\
\text { controlled }\end{array}$ & 57 & Music therapy & Nasal surgery & $\begin{array}{l}\text { Postoperative } \\
\text { pain }\end{array}$ & $\begin{array}{l}\text { Reduction in postoperative pain } \\
(P<0.0001) \text {, systolic blood } \\
\text { pressure, heart rate, and } \\
\text { required analgesics } \\
\text { compared to the no-music } \\
\text { therapy group }\end{array}$ \\
\hline
\end{tabular}

studies examining the effects of aromatherapy, hypnosis, and music therapy.

\section{DISCUSSION}

Postoperative pain management is an important consideration for otolaryngology providers, as pain affects patient comfort, surgical experience, outcomes, wound healing, and family perception. Although some providers remain skeptical about the efficacy of using CAM to manage symptoms and improve experiences, contemporary studies suggest a role for CAM in the perioperative management of otolaryngologic surgeries. In light of the concerns regarding pain medication addiction in the United States, providers should consider the risks of overprescribing narcotics to patients following elective otolaryngologic surgeries. The use of CAM therapies in the perioperative period offers an alternative means for pain control without the underlying safety concerns.

Wise et al demonstrated that postoperative pain levels were low in patients who had undergone nasal and sinus surgeries, and that the majority of patients had leftover medication, suggesting that surgeons may prescribe excess pain medication. ${ }^{41}$ Alam et al found that patients who were prescribed opioids after low-risk ambulatory surgeries were $44 \%$ more likely to become long-term opioid users than patients who did not receive prescriptions for opioids. ${ }^{42}$ These significant findings warrant examining alternative means to achieving adequate pain control.

A limitation of this review is the paucity of published data examining negative or poor outcomes with the use of CAM in the perioperative period in otolaryngologic surgery. Future studies should examine the amount of time necessary for
CAM administration, the cost and cost-effectiveness of treatment, the resources available for providers seeking to implement CAM in their practices, and the viability of these therapies once integrated into surgical practice.

\section{CONCLUSION}

CAM therapies such as acupuncture, aromatherapy, hypnosis, and music therapy have shown encouraging results when used in perioperative care for otolaryngology procedures. Evidence indicates that these techniques have value in relieving preoperative anxiety, postoperative pain, and PONV. These effects may have important clinical implications. Additional study is warranted.

\section{ACKNOWLEDGMENTS}

The authors have no financial or proprietary interest in the subject matter of this article.

\section{REFERENCES}

1. Fleckenstein J, Baeumler PI, Gurschler C, et al. Acupuncture for post anaesthetic recovery and postoperative pain: study protocol for a randomised controlled trial. Trials. 2014 Jul 21;15:292. doi: 10.1186/1745-6215-15-292.

2. Shakeel M, Bruce J, Jehan S, McAdam TK, Bruce DM. Use of complementary and alternative medicine by patients admitted to a surgical unit in Scotland. Ann R Coll Surg Engl. 2008 Oct;90 (7):571-576. doi: 10.1308/003588408X301046.

3. Ventola CL. Current issues regarding complementary and alternative medicine (CAM) in the United States. Part 1: the widespread use of CAM and the need for better-informed health care professionals to provide patient counseling. $P T$. 2010 Aug;35(8):461-468. 
4. Usichenko $T$, Dinse $M$, Hermsen $M$, Witstruck T, Pavlovic $D$, Lehmann $\mathrm{Ch}$. Auricular acupuncture for pain relief after total hip arthroplasty - a randomized controlled study. Pain. 2005 Apr;114(3):320-327.

5. Lee YR, Shin HS. Effectiveness of ginger essential oil on postoperative nausea and vomiting in abdominal surgery patients. J Altern Complement Med. 2017 Mar;23(3):196-200. doi: 10.1089/acm.2015.0328.

6. Lambert SA. The effects of hypnosis/guided imagery on the postoperative course of children. J Dev Behav Pediatr. 1996 Oct;17(5):307-310.

7. Anderson FW, Johnson CT. Complementary and alternative medicine in obstetrics. Int J Gynaecol Obstet. 2005 Nov;91 (2):116-124.

8. Sun Y, Gan TJ, Dubose JW, Habib AS. Acupuncture and related techniques for postoperative pain: a systematic review of randomized controlled trials. Br J Anaesth. 2008 Aug;101 (2):151-160. doi: 10.1093/bja/aen146.

9. Astin JA. Why patients use alternative medicine: results of a national study. JAMA. 1998 May 20;279(19):1548-1553.

10. Gouin JP, Kiecolt-Glaser JK. The impact of psychological stress on wound healing: methods and mechanisms. Immunol Allergy Clin North Am. 2011 Feb;31(1):81-93. doi: 10.1016/j. iac.2010.09.010.

11. Shaikh SI, Nagarekha D, Hegade G, Marutheesh M. Postoperative nausea and vomiting: a simple yet complex problem. Anesth Essays Res. 2016 Sep-Dec;10(3):388-396.

12. Harsoor S. Emerging concepts in post-operative pain management. Indian J Anaesth. 2011 Mar;55(2):101-103. doi: 10.4103/0019-5049.79872.

13. Tsao GJ, Messner AH, Seybold J, Sayyid ZN, Cheng AG, Golianu B. Intraoperative acupuncture for posttonsillectomy pain: a randomized, double-blind, placebo-controlled trial. Laryngoscope. 2015 Aug;125(8):1972-1978. doi: 10.1002/ lary. 25252 .

14. Chernyak GV, Sessler DI. Perioperative acupuncture and related techniques. Anesthesiology. 2005 May;102(5):1031-1049; quiz 1077-1078.

15. Ernst $G$, Strzyz H, Hagmeister H. Incidence of adverse effects during acupuncture therapy-a multicenter survey. Complement Ther Med. 2003 Jun;11(2):93-97.

16. Chung A, Bui L, Mills E. Adverse effects of acupuncture. Which are clinically significant? Can Fam Physician. 2003 Aug;49:985989.

17. Shin HC, Kim JS, Lee SK, et al. The effect of acupuncture on postoperative nausea and vomiting after pediatric tonsillectomy: a meta-analysis and systematic review. Laryngoscope. 2016 Aug;126(8):1761-1767. doi: 10.1002/ lary. 25883.

18. Moeen SM. Could acupuncture be an adequate alternative to dexamethasone in pediatric tonsillectomy? Paediatr Anaesth. 2016 Aug;26(8):807-814. doi: 10.1111/pan.12933.

19. Ochi JW. Acupuncture instead of codeine for tonsillectomy pain in children. Int J Pediatr Otorhinolaryngol. 2013 Dec;77 (12):2058-2062. doi: 10.1016/j.ijporl.2013.10.008.

20. Gilbey P, Bretler S, Avraham Y, Sharabi-Nov A, Ibrgimov S, Luder A. Acupuncture for posttonsillectomy pain in children: a randomized, controlled study. Paediatr Anaesth. 2015 Jun;25 (6):603-609. doi: 10.1111/pan.12621.

21. Cho HK, Park IJ, Jeong YM, Lee YJ, Hwang SH. Can perioperative acupuncture reduce the pain and vomiting experienced after tonsillectomy? A meta-analysis. Laryngoscope. 2016 Mar;126 (3):608-615. doi: 10.1002/lary.25721.
22. Pfister DG, Cassileth BR, Deng GE, et al. Acupuncture for pain and dysfunction after neck dissection: results of a randomized controlled trial. J Clin Oncol. 2010 May 20;28(15):2565-2570. doi: 10.1200/JCO.2009.26.9860.

23. Deganello A, Battat N, Muratori E, et al. Acupuncture in shoulder pain and functional impairment after neck dissection: a prospective randomized pilot study. Laryngoscope. 2016 Aug;126(8):1790-1795. doi: 10.1002/lary.25921.

24. Grech D, Li Z, Morcillo P, et al. Intraoperative low-frequency electroacupuncture under general anesthesia improves postoperative recovery in a randomized trial. J Acupunct Meridian Stud. 2016 Oct;9(5):234-241. doi: 10.1016/j.jams.2016.03.009.

25. Sahmeddini MA, Farbood A, Ghafaripuor S. Electroacupuncture for pain relief after nasal septoplasty: a randomized controlled study. J Altern Complement Med. 2010 Jan;16(1):53-57. doi: 10.1089/acm.2009.0288.

26. Tong QY, Ma W, Shen WD, Zhang ZJ, Zhao C. Analgesic effect of acupuncture compound anesthesia in functionality nasal endoscopic sinus surgery [in Chinese]. Zhongguo Zhen Jiu. 2012 Sep;32(9):815-818.

27. Stea S, Beraudi A, De Pasquale D. Essential oils for complementary treatment of surgical patients: state of the art. Evid Based Complement Alternat Med. 2014;2014:726341. doi: 10.1155/2014/726341.

28. Ni CH, Hou WH, Kao CC, et al. The anxiolytic effect of aromatherapy on patients awaiting ambulatory surgery: a randomized controlled trial. Evid Based Complement Alternat Med. 2013;2013:927419. doi: 10.1155/2013/927419.

29. Perry R, Terry R, Watson LK, Ernst E. Is lavender an anxiolytic drug? A systematic review of randomized clinical trials. Phytomedicine. 2012 Jun 15;19(8-9):825-835. doi: 10.1016/j. phymed.2012.02.013.

30. Kianpour M, Mansouri A, Mehrabi T, Asghari G. Effect of lavender scent inhalation on prevention of stress, anxiety and depression in the postpartum period. Iran J Nurs Midwifery Res. 2016 Mar-Apr;21(2):197-201. doi: 10.4103/1735-9066.178248.

31. Soltani R, Soheilipour S, Hajhashemi V, Asghari G, Bagheri M, Molavi M. Evaluation of the effect of aromatherapy with lavender essential oil on post-tonsillectomy pain in pediatric patients: a randomized controlled trial. Int $J$ Pediatr Otorhinolaryngol. 2013 Sep;77(9):1579-1581. doi: 10.1016/j. ijporl.2013.07.014.

32. Wotman M, Levinger J, Leung L, Kallush A, Mauer E, Kacker A. The efficacy of lavender aromatherapy in reducing preoperative anxiety in ambulatory surgery patients undergoing procedures in general otolaryngology. Laryngoscope Investig Otolaryngol. 2017 Nov 8;2(6):437-441. doi: 10.1002/lio2.121.

33. Kuttner L. Pediatric hypnosis: pre-, peri-, and post-anesthesia. Paediatr Anaesth. 2012 Jun;22(6):573-577. doi: 10.1111/j.14609592.2012.03860.x.

34. Saadat H, Drummond-Lewis J, Maranets I, et al. Hypnosis reduces preoperative anxiety in adult patients. Anesth Analg. 2006 May;102(5):1394-1396.

35. Erel O, Erel KV. Hypnosis. Meandros Med Dent J. 2017;18(3):7679. doi: $10.4274 /$ meandros. 2555.

36. Accardi MC, Milling LS. The effectiveness of hypnosis for reducing procedure-related pain in children and adolescents: a comprehensive methodological review. J Behav Med. 2009 Aug;32(4):328-339. doi: 10.1007/s10865-009-9207-6.

37. Rapkin DA, Straubing M, Holroyd JC. Guided imagery, hypnosis and recovery from head and neck cancer surgery: an exploratory study. Int J Clin Exp Hypn. 1991 Oct;39(4):215-226. 
38. Kahloul M, Mhamdi S, Nakhli MS, et al. Effects of music therapy under general anesthesia in patients undergoing abdominal surgery. Libyan J Med. 2017 Dec;12(1):1260886. doi: 10.1080/ 19932820.2017 .1260886$.

39. Conrad C, Niess H, Jauch KW, Bruns CJ, Hartl W, Welker L. Overture for growth hormone: requiem for interleukin-6? Crit Care Med. 2007 Dec;35(12):2709-2713.

40. Tse MM, Chan MF, Benzie IF. The effect of music therapy on postoperative pain, heart rate, systolic blood pressures and analgesic use following nasal surgery. J Pain Palliat Care Pharmacother. 2005;19(3):21-29.
41. Wise SK, Wise JC, DelGuadio JM. Evaluation of postoperative pain after sinonasal surgery. Am J Rhinol. 2005 Sep-Oct;19 (5):471-477.

42. Alam A, Gomes T, Zheng H, Mamdani MM, Juurlink DN, Bell CM. Long-term analgesic use after low-risk surgery: a retrospective cohort study. Arch Intern Med. 2012 Mar 12;172(5):425-430. doi: 10.1001/archinternmed.2011.1827.

This article meets the Accreditation Council for Graduate Medical Education and the American Board of Medical Specialties Maintenance of Certification competencies for Patient Care, Medical Knowledge, and Practice-Based Learning and Improvement. 